\section{A new species of the genus Otacilia (Araneae: Corinnidae) from Japan}

\author{
Takahide Kamura
}

\author{
Biological Laboratory, Otemon Gakuin University, 2-1-15, \\ Nishi-Ai, Ibaraki, Osaka, 567-8502 Japan \\ E-mail: kamura@res.otemon.ac.jp
}

\begin{abstract}
A new corinnid species is described from Japan under the name of Otacilia mustela. Specimens of the new species can be distinguished from those of $O$. vulpes (Kamura 2001) by their small and narrow retrolateral tibial apophysis in male palp, and relatively short and wide spermathecae in female internal genitalia.
\end{abstract}

Key words - Corinnidae, Otacilia, new species, Japan

Spiders of the genus Otacilia are distributed in East Asia and South East Asia. Up to the present, 14 species of the genus were recorded from the regions, and of these 6 species occur in Japan (Deeleman-Reinhold 2001, Kamura 2004; for the details of Otacilia see Kamura 2004).

Recently I had opportunities to examine many specimens of a certain species of Otacilia collected from Chiba and Kanagawa Prefectures and Tokyo, and recognized that although the features of female epigynum of the specimens are similar to those of Otacilia vulpes (Kamura 2001), judging from the male palpal structure of the specimens they belong to an undescribed species. Furthermore, after reexamining two female specimens previously reported as $O$. vulpes in my paper (Kamura 2004), I detected that they also belong to the undescribed species. In this paper, I describe the species as new to science.

The type specimens of the new species described in this paper are deposited in the collection of the Department of Zoology, National Museum of Nature and Science, Tokyo (NSMT).

The abbreviations used in this paper are as follows: ALE, anterior lateral eye; AME, anterior median eye; d, dorsal; MOA, median ocular area; pl, prolateral; PLE, posterior lateral eye; PME, posterior median eye; pv, proventral; rv, retroventral. Eye size means length of long axis of an eye, but measurement of posterior median eye was made at horizontal level.

I would like to express my sincere thanks to Mr. Shingo Hatsushiba, Tokyo, Mr. Ken-ichi Kumada, Mie, and Dr. Akio Tanikawa, the University of Tokyo, for offering the specimens used in this study.
Otacilia mustela $\mathrm{n}$. $\mathrm{sp}$.

[Japanese name: Akagane-urashimagumo]

(Figs. 1-4)

Type series. Holotype: $\sigma^{\top}$, Yoshiohiratsuka, Kamogawashi, Chiba Pref., Japan, 18-23.V.2005 (by pitfall traps), T. Miyashita et al. leg. (NSMT-Ar 7849). Paratypes: 40, same data as the holotype (NSMT-Ar 7850-7853); 5우, Izumi, Kamogawa-shi, Chiba Pref., Japan, same date and collectors as the holotype (NSMT-Ar 7854-7858).

Other specimens examined. 10, same data as the holotype. 4우, same data as the female paratypes. $20^{\pi}$, Hoshiibata, Otaki-machi, Isumi-gun, Chiba Pref., Japan, same date and collectors as the holotype. 1ð, Motohachiojimachi, Hachioji-shi, Tokyo, Japan, 4.V.2006, R. Kono leg. $2{ }^{`} 2$ 우, Fudakake, Susugaya, Kiyokawa-mura, Aikou-gun, Kanagawa Pref., Japan, 17.V.1978, K. Kumada leg. 1우, Hakone-machi, Ashigarashimo-gun, Kanagawa Pref., Japan, 31.VII.1983, K. Kumada leg.

Specimens misidentified with Otacilia vulpes in Kamura (2004). 1우, Hachioji-joshi, Hachioji-shi, Tokyo, Japan, 21.V.1989, K. Kumada leg. 1우, Kumomi, Matsuzaki-cho, Kamo-gun, Shizuoka Pref., Japan, 27.VII.1992, S. Inaba leg.

Diagnosis. This new species resembles Otacilia vulpes (Kamura 2001) in general appearance. Males of this new species can easily be separated from those of $O$. vulpes by their retrolateral tibial apophysis small and narrow (Figs. 12). Females of these two species are very similar to each other in the structure of epigynum and internal genitalia, but spermathecae are somewhat shorter and wider in this new species (Figs. 3-4) than in O. vulpes (Kamura 2001, figs. $6^{-}$ 7).

Description. Measurements [based on the male holotype and one of the female paratypes (NSMT-Ar 7854), in mm]. Body length ${ }^{7} 3.56$, 우.20. Carapace length $\lesssim 1.72$, 우1.70; width $\lesssim 1.44$, 우1.44. Abdomen length ${ }^{\rtimes} 1.84$, 우2.50; width

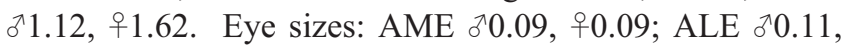

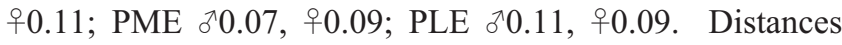
between eyes: AME-AME ${ }^{`} 0.05$, 우0.04; AME-ALE ${ }^{\top} 0.01$, 우0.01; PME-PME ðð0.11, 우0.07; PME-PLE ð00.07, 우0.05; ALE-PLE $\gtrsim 0.09$, 우0.07. MOA anterior width ${ }^{\top} 0.21$, 우 0.21 ; posterior width $\delta^{7} 0.25$, 우 0.25 ; length $\diamond^{\top} 0.25$, 우 0.24 . Clypeus height $\delta^{\top} 0.12$, 우 0.11 . Length of legs as in Table 1 .

Variation (in mm). $\sigma^{\pi}$ : body length 2.64-3.75; carapace length 1.31-1.80, width 1.08-1.53; abdomen length $1.33^{-}$ 2.00 , width $0.85-1.38$. 우 : body length $3.20-4.20$; carapace length $1.38^{-1.70}$, width $1.15^{-1.44}$; abdomen length $1.83^{-}$ 2.50, width 1.15-1.62.

Number of spines on legs. $\delta$ : femora I-IV d 1; femur I pl 3 or 4; femur II pl 2 (rarely 1); tibia I pv 6 or 7, rv 6 or 7; tibia II pv 6 or 7, rv 6 (rarely 5 or 7); metatarsus I pv 4, rv 4 ; metatarsus II pv 4, rv 3 or 4 . 우: femora I-IV d 1; femur I pl 4 (rarely 3); femur II pl 2 or 3 (rarely 1); tibia I pv 6 or 7 (rarely 5 or 8 ), rv 7 or 8 ; tibia II pv 6 or 7 , rv 6 


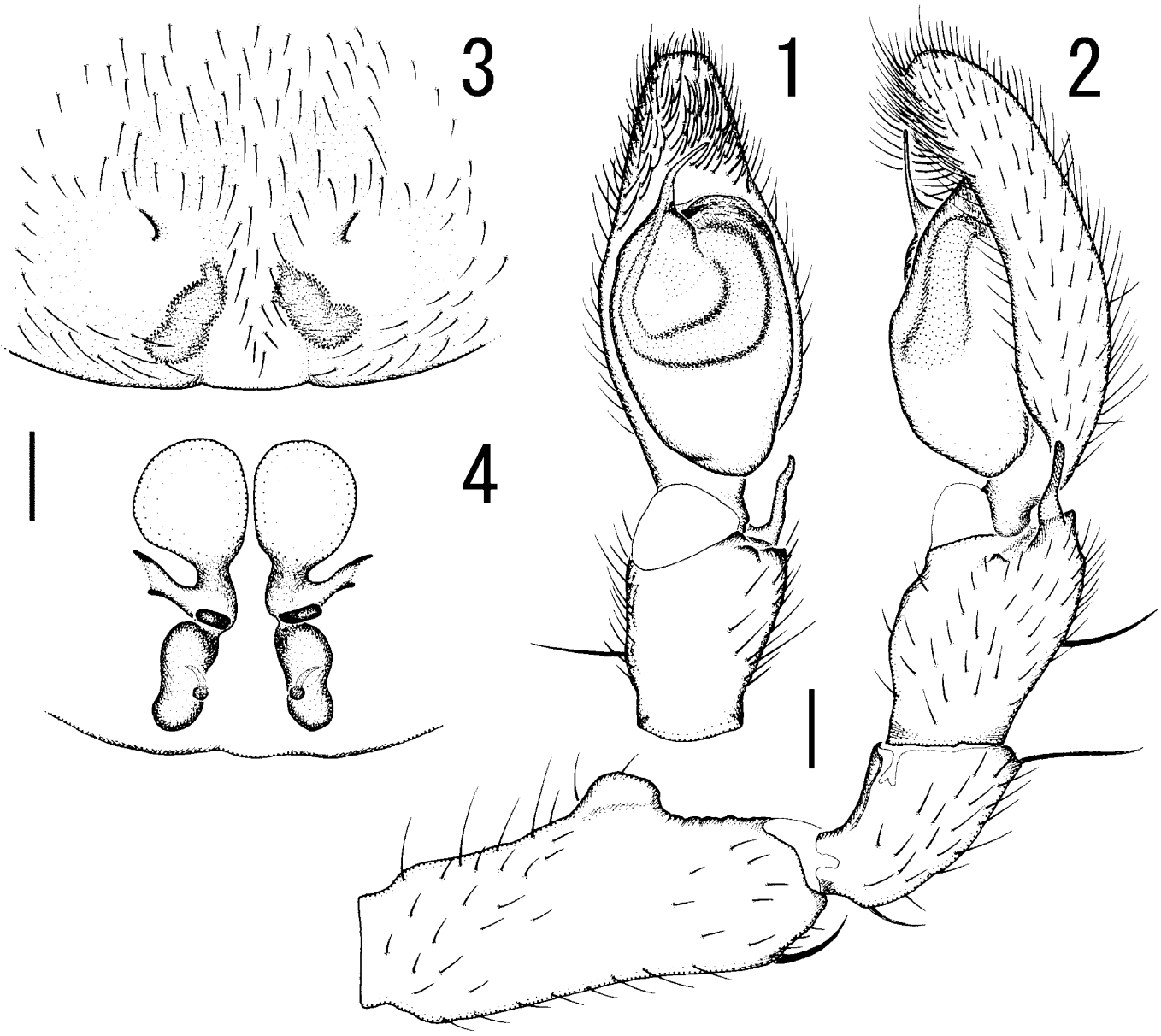

Figs. 1-4. Otacilia mustela n. sp. - 1, Left male palp (holotype), ventral view; 2, same, retrolateral view; 3, epigynum (paratype NSMTAr 7854), ventral view; 4, female internal genitalia (paratype NSMT-Ar 7855), dorsal view. (Scales: $0.1 \mathrm{~mm}$ )

Table 1. Measurements of legs of Otacilia mustela n. sp. [male holotype/female paratype (NSMT-Ar 7854), in mm].

\begin{tabular}{ccccccc}
\hline Leg & Femur & Patella & Tibia & Metatarsus & Tarsus & Total \\
\hline I & $1.62 / 1.66$ & $0.62 / 0.64$ & $1.62 / 1.68$ & $1.44 / 1.56$ & $0.66 / 0.75$ & $5.96 / 6.29$ \\
II & $1.36 / 1.40$ & $0.54 / 0.58$ & $1.22 / 1.30$ & $1.18 / 1.28$ & $0.65 / 0.73$ & $4.95 / 5.29$ \\
III & $1.12 / 1.18$ & $0.50 / 0.52$ & $0.88 / 0.92$ & $1.12 / 1.20$ & $0.62 / 0.65$ & $4.24 / 4.47$ \\
IV & $1.62 / 1.76$ & $0.56 / 0.59$ & $1.44 / 1.54$ & $1.75 / 1.92$ & $0.82 / 0.90$ & $6.19 / 6.71$ \\
\hline
\end{tabular}

(rarely 7); metatarsus I pv 4 (rarely 5), rv 4; metatarsus II pv 4 , rv 3 or 4.

Chelicera with two spines on anterior side; promargin of fang furrow with three teeth and retromargin with two teeth. Male abdomen with a dorsal scutum covering almost whole abdomen. Female abdomen without a dorsal scutum. Male palp with embolus narrow, and retrolateral tibial apophysis rather small and narrow (Figs. 1-2). Epigynum as shown in Fig. 3. Female internal genitalia with spermathecae anteriorly convergent or nearly parallel to each other (Figs. 3-4).

Color. Cephalothorax and appendages reddish brown, but femora of legs darker. Abdomen dark brown with venter paler, and postero-dorsal part whitish yellow. Spinnerets yellowish brown. Male abdomen with a scutum dark reddish brown

Distribution. Japan (Honshu).

Etymology. The specific name meaning a weasel is a noun in apposition.

\section{References}

Deeleman-Reinhold, C. L. 2001. Forest Spiders of South East Asia. Koninklijke Brill NV, Leiden, 591 pp, 8 pls.

Kamura, T. 2001. Seven species of the families Liocranidae and Corinnidae (Araneae) from Japan and Taiwan. Acta Arachnol., 50: 49-61.

Kamura, T. 2004. Spiders of the genus Otacilia (Araneae: Corinnidae) from Japan. Acta Arachnol., 53: 87-92.

Received March 25, 2008 / Accepted May 11, 2008 